OPEN ACCESS

Edited by:

Luigi Janiri,

Catholic University of the Sacred

Heart, Italy

Reviewed by:

Martin Zack,

Centre for Addiction and Mental

Health (CAMH), Canada

Lorenzo Moccia

Agostino Gemelli University Polyclinic,

Italy

${ }^{*}$ Correspondence:

Human-Friedrich Unterrainer human.unterrainer@univie.ac.at

Specialty section:

This article was submitted to

Addictive Disorders,

a section of the journal

Frontiers in Psychiatry

Received: 08 November 2018

Accepted: 08 August 2019

Published: 05 September 2019

Citation:

Fuchshuber J, Hiebler-Ragger M,

Kresse A, Kapfhammer H-P and Unterrainer HF (2019) The Influence of Attachment Styles and Personality

Organization on Emotional Functioning After Childhood Trauma.

Front. Psychiatry 10:643.

doi: 10.3389/fpsyt.2019.00643

\section{The Influence of Attachment Styles and Personality Organization on Emotional Functioning After Childhood Trauma}

\author{
Jürgen Fuchshuber 1,2, Michaela Hiebler-Ragger 1,2, Adelheid Kresse ${ }^{3}$, \\ Hans-Peter Kapfhammer ${ }^{2}$ and Human Friedrich Unterrainer ${ }^{1,2,4 *}$ \\ ${ }^{1}$ Center for Integrative Addiction Research (CIAR), GrünerKreis Society, Vienna, Austria, ${ }^{2}$ University Clinic for Psychiatry and \\ Psychotherapeutic Medicine, Medical University Graz, Graz, Austria, ${ }^{3}$ Institute for Pathophysiology und Immunology, Medical \\ University Graz, Graz, Austria, ${ }^{4}$ Department of Religious Studies, University of Vienna, Vienna, Austria
}

Background: Current literature suggests a tenuous link among childhood trauma, personality organization, adult attachment, and emotional functioning in various psychiatric disorders. However, empirical research focusing on the interaction of these concepts is sparse. Therefore, this study intends to investigate the influence of personality organization and attachment dimensions on the relationship between childhood maltreatment and emotional functioning in adult life. To assess emotional functioning, we adopted the Affective Neuroscience model of primary emotions, comprising SEEKING, FEAR, ANGER, SADNESS, CARE, and PLAY.

Methods: The total sample consisted of 616 nonclinical adults (Age: $M=30 ; S D=9.53$; $61.9 \%$ female). Path analysis was applied to investigate interactions among childhood trauma, personality organization, adult attachment, and primary emotion dispositions.

Results: The findings suggest that childhood trauma significantly predicted deficits in personality organization and insecure attachment (all $p<0.001$ ). Furthermore, a reduced level of personality organization was significantly associated with increased ANGER $(p<0.001)$, whereas adult attachment substantially predicted primary emotion dispositions in general. Moreover, the results indicate significant mediational effects of personality organization and attachment dimensions on the relationship between childhood trauma and primary emotions $(p<0.01)$. The final model was able to explain $48 \%$ of the variance in SADNESS, 38\% in PLAY, 35\% in FEAR, 28\% in CARE, 14\% in ANGER, and 13\% in SEEKING.

Discussion: The findings contribute to the understanding of the relationship between childhood maltreatment and impaired emotional functioning in adult life. Furthermore, the importance of personality organization and attachment dimensions for emotion regulation is underlined. Consequently, the treatment of patients with childhood trauma should focus on facilitating the development of more secure attachment patterns and increased personality functioning to improve overall emotional functioning.

Keywords: adult attachment, personality organization, structural equation modeling, childhood trauma, primary emotions, affect regulation, mediation 


\section{INTRODUCTION}

There is considerable evidence linking childhood maltreatment to a wide range of adult psychopathology (1). In accordance with this, a recent review by Teicher and Samson (2) suggested that childhood trauma is substantially related with morphological alterations in a number of brain regions, specifically the anterior cingulate, dorsal lateral prefrontal and orbitofrontal cortexes, the corpus callosum, and the hippocampus. Furthermore, childhood trauma is linked with enhanced amygdala response to emotional cues and conflict processing as well as diminished striatal response to anticipated rewards. In this context, converging results suggest that the association between childhood trauma and adult psychopathology might be mediated by disturbances in the neurobiological development related to cognitive control and emotion regulation (3-5). Empirically, childhood trauma is often assessed by the retrospective amount of emotional, physical, and sexual abuse, as well as emotional and physical neglect and deprivation (6).

With regard to emotional functioning, Affective Neuroscience (AN) proposes a framework of interdependently connected structures composed of primary, secondary, and tertiary processes (7-9). Primary processes consist of largely subcortically located basic emotions, serving as the primary motivational system of behavior. Secondary processes are linked to the limbic system and basal ganglia. These include unconscious and conditioned behavioral traits, like personality functions, object relations, and attachment patterns. Tertiary processes are predominantly neocortically based and summarize a broad spectrum of higher order cognitive functions like mentalization, mindfulness, and spirituality. Regarding the primary process foundation of personality, AN emphasizes the importance of seven neurobiologically discrete basic emotion circuits, bridging the boundary between physiological and psychological experience (7). These include SEEKING, LUST, ANGER, FEAR, SADNESS (or PANIC/ GRIEF), PLAY, and CARE. With the exception of LUST, these primary emotion systems can be measured on a language-based conscious level with the Affective Neuroscience Personality Scales (ANPS) developed by Davis, Panksepp, and Normansell (10). The clinical importance of these primary emotions is underlined by their role in a multitude of psychiatric disorders, including depression (11-13), substance use disorders (14), Internet addiction (15), and autism (16). Furthermore, a recent twin study by Melchers et al. (17) implies a significant heritability of primary emotion dispositions and emphasizes the influence of environmental factors. Recent findings by Fuchshuber et al. (12) suggested a substantial association between childhood trauma and despair, which was composed of low SEEKING and high SADNESS, as proposed by Watt and Panksepp (18) and Zellner et al. (19).

Traditionally, the development of secure attachment has been linked to the genesis of emotional functioning (20). Thereby, Bowlby (21) observed that infants who were not able to establish a secure attachment to their caregiver were at higher risk for the emergence of developmental disorders, severe depression, and delinquent behavior. In accordance with this, attachment theory assumes that the development of affect regulation is linked to the early nonverbal communication between infant and primary caregiver $(22,23)$. Ideally, primary caregivers perceive the nonverbal affective expressions of the infant and coregulate these through symbolic mirroring and by providing physical as well as verbal comfort. This process helps the infant to tolerate its intense and primary nonverbal emotions. The repeated experience of this process is gradually internalized by the infant, which leads to the development of a positive inner working model of the self and others. These inner working models provide an internalized secure base, which enables the individual to regulate emotions in a relatively autonomous and functional way (24). Furthermore, secure attachment helps the individual to form stable and functional relationships, allowing the individual to regulate emotions with the help of others (25). In accordance with this, a secure adult attachment style might be defined by a pattern of comfortableness with intimacy, low anxiety of being rejected and unloved, as well as the ability to depend on others and having others depending on oneself (26). However, internalized traumatic early experiences lead to corresponding inner working models and insecure attachment patterns that obstruct the functional regulation of emotions $(23,27-29)$.

In line with this, $(9,30)$ proposed internalized object relations as the building blocks of the mind. Therefore, object relations consist of self-representations and object representations and affects connecting both. Similar to the inner working model of self and others in attachment theory, in Kernberg's view, object relations are conceptualized as influenced by early relationship experiences $(9,24)$. Yet, in contrast to attachment theory, Kernberg assumes that memories of early relationship experiences in adults are distorted by elements of fantasy regarding the primary caregiver. Furthermore, he emphasizes the interaction between the infants temperament and its environment $(9,31,32)$. In accordance with this, the process of internalization of object relations gradually shapes mental structures and personality organization through consecutive layering sequences.

Kernberg's $(32,33)$ model of personality organization differentiates among three dimensions of dysfunctioning: (1) identity diffusion, which describes deficits regarding the coherence of internalized representations of oneself and others; (2) primitive defense mechanisms, meaning the dominance of early defense formations related to splitting; and (3) reality testing, indicating the ability to separate between the internal and external world. Moreover, he suggested that personality organization might be differentiated into three broad categories termed the neurotic, borderline, and psychotic level of organization. In this context, "borderline organization," which is conceptually related but not identical with borderline personality disorder (BPD), is linked to increased identity diffusion and predominant primitive defense mechanisms, combined with a mostly intact reality testing. In contrast, a decreased ability for reality testing is linked to a psychotic organization. However, all three concepts are theoretically interlocked and display an overall continuum of personality functioning (34). Research suggests that a low level of personality organization is associated with increased aggressive dyscontrol and negative affect as well as decreased positive affect and dysphoria (35). 
It might be expected, because of similar theoretical foundations and implications, that both adult attachment and personality organization are significantly interrelated. Nonetheless, research investigating the link between self-rating measures of both concepts has been sparse and studies have been made predominantly on theoretical grounds (36-38). Most empirical studies focused on the relationship between BPD and adult attachment. Their results suggested robust associations between BPD and insecure attachment patterns (39), but they did not reveal a single attachment style specifically predicting BPD (40). Moreover, deficits within the attachment system are seen as core features of BPD (28). Regarding borderline personality organization, a study by Fischer-Kern et al. (41), which investigated links between reflective functioning (42), measured by the Adult Attachment interview (43), and personality organization, measured by the Structured Interview of Personality Organization (44), found moderate associations between deficits in reflective functioning and personality organization. In addition, Hiebler-Ragger et al. (45) reported significant correlations between borderline organization and adult attachment operationalized with self-rating measurements.

\section{Research Question and Hypothesis}

To map the relationship among childhood trauma, attachment, personality organization, and emotional functioning, this study applied path analysis. This statistical technique enables the investigation of simultaneous links between different concepts. Based on the research outlined above, the following hypotheses were formulated. Increased childhood trauma predicts more unsecure attachment patterns, deficits in personality organization, and decreased emotional functioning, as measured by basic emotion dispositions. Furthermore, unsecure attachment patterns and deficits in personality organization were expected to be associated with decreased emotional functioning. Therefore, we tested the hypothesis that attachment styles and personality organizations have a mediational role in the relationship between childhood trauma and emotional functioning. The conceptual framework for the hypotheses is outlined in Figure 1. Furthermore, we applied a multigroup path analysis approach to test if healthy participants differed from participants with a psychiatric diagnosis regarding the relationships in the path model.

\section{MATERIALS AND METHODS}

\section{Procedure}

The sample was recruited through various social networks. Informed consent was acquired before each participant filled in the test form that included demographic questions as well as the standardized questionnaires described below. The data were acquired via the online-survey platform LimeSurvey ${ }^{\odot}$. Data were analyzed from all participants who were aged between 18 and 69 years, spoke German fluently, and filled in every questionnaire. Overall, 1,502 individuals responded to the online survey, however, 874 discontinued the participation before completion, whereas 12 participants did not meet the required age for participation. The study was carried out in accordance with the Declaration of Helsinki. Ethical approval was granted by the Ethics Committee of the Medical University of Graz, Graz, Austria. The recruitment of participants was carried out between 02.04.2017 and 19.03.2018.

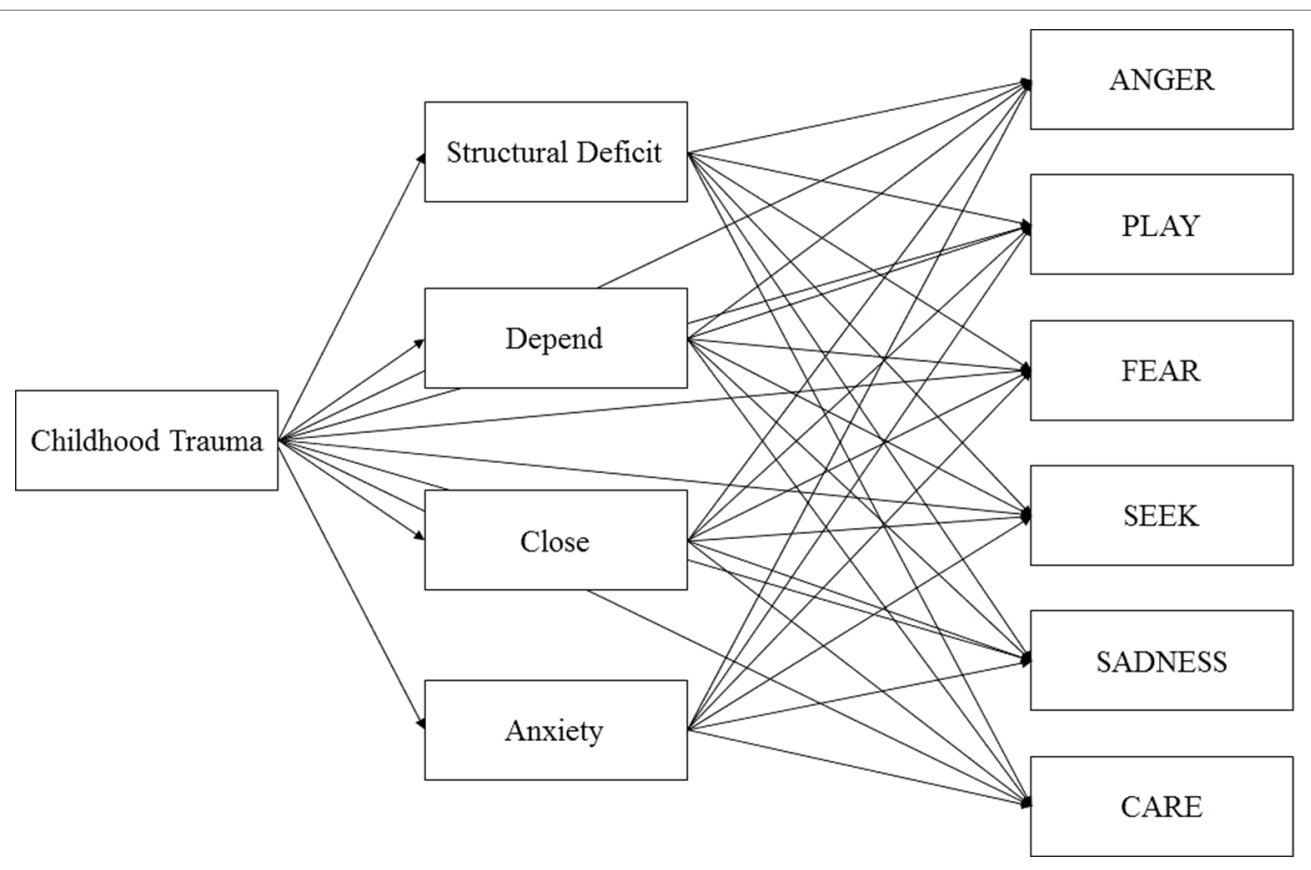

FIGURE 1 | Initial model of Childhood Trauma, Structural Deficit, Adult Attachment, and Primary Emotions controlled for Age and Sex. 


\section{Psychometric Assessment Childhood Trauma}

The Childhood Trauma Questionnaire (CTQ) (6) [German version by Wingenfeld et al. (46)] is a 28 -item self-report measure of traumatizing childhood experiences, comprising "Emotional Abuse," "Physical Abuse," "Sexual Abuse," and "Emotional Neglect." A total "Childhood Trauma" score can be calculated based on answers to the questionnaire. Because of poor reliability, the subscale "Physical Neglect" was excluded in this study (47). It employs a 1 ("never") to 5 ("very often") Likert scale, with higher scores indicating more severe abuse or neglect. The subscales showed good to excellent internal consistencies with Cronbach's alpha ranging from 0.74 to 0.91. The total score exhibited an excellent internal consistency with Cronbach's alpha of 0.93 .

\section{Emotional Functioning}

The ANPS (10) [German version by Ref. (48); see Ref. (49), for the most recent version] is a self-report questionnaire that measures behavioral traits related to the concept of subcortical primary emotion circuits developed by Panksepp (50). Therefore, this questionnaire comprises the subscales SEEKING, SADNESS, FEAR, RAGE, CARE, and PLAY and an additional scale for "Spirituality." It consists of, overall, 110 items, with 14 items for each subscale and is rated on a 4-point scale ranging from 1 ("strongly disagree") to 4 ("strongly agree"). SEEKING summarizes the disposition toward feelings of positive curiosity toward new experiences, the tendency to explore, and a sense of being able to achieve relevant goals. PLAY measures the trait of being protracted toward games with physical contact, laughter, fun, as well as being generally happy and joyful. SADNESS operationalizes the tendency of feeling separation distress, loneliness, and sorrow. CARE operationalizes the individual's tendency toward feelings of empathy, caring for children, people in need and animals, and a general enjoyment of being needed by others. FEAR measures the individuals' tendency toward feelings of anxiety, tenseness, worries, and ruminations. ANGER is conceptualized as being easily frustrated and irritated, the frequent expression of anger in a verbal or physical way, the experience of being angry due to frustrations, and being unable to calm down. All scales showed acceptable to good internal consistencies, with Cronbach's alpha ranging from 0.78 (SADNESS) to 0.89 (SEEKING). Because of our hypotheses, the subscale Spirituality was not analyzed in this study.

\section{Personality Organization}

The 16-Item Inventory of Personality Organization (IPO-16) [German version by Wingenfeld et al. (34)], is a self-report measurement of deficits within personality structure. The questionnaire is theoretically grounded in Otto Kernberg's (32) model of personality organization. The IPO-16 is composed of three subscales: (1) "Identity Diffusion," which measures the integrity of the representations of oneself and others; (2) Dominance of primitive defense mechanisms, such as splitting, denial, projection, and dissociation ("Primitive Defense"); and (3) the capacity to differentiate between internal and external stimuli ("Reality Testing"). A total score of structural deficits can be generated with this instrument. The items are rated on a 5-point Likert scale ranging from 1 ("never") to 5 ("always").
Internal consistencies for the subscales were acceptable ranging from $\alpha=0.74$ to $\alpha=0.80$. The total score showed good internal consistency with a Cronbach's alpha of 0.88 .

\section{Adult Attachment}

The Adult Attachment Scale (AAS) (51) is a self-report questionnaire based on the assumption that early attachment experiences form relatively stable inner attachment working models that influence individual needs and behavior in later relationships (21). The AAS consists of three subscales measuring anxiety about being rejected or unloved ("Anxiety"), comfort with closeness ("Close"), and comfort with depending on others ("Depend"). The German version of the AAS (26) is composed of 15 items (five items per subscale) and is rated on a 5-point Likert scale ranging from 1 ("strongly disagree") to 5 ("strongly agree"). Cronbach's alpha for the subscales ranged between 0.81 and 0.87 .

\section{Statistical Analysis and Analysis Strategy}

The path analysis and multigroup path analysis were conducted with AMOS 18. SPSS 17.0 was used for data management, descriptive statistics, and bivariate correlations, which assessed the strength of the relations among all variables. In the next step, data were fitted to an initial path model that included the following paths: Childhood Trauma to the attachment scales Depend, Anxiety, and Close; Childhood Trauma to Structural Deficit; Childhood Trauma to all primary emotions; attachment scales to all primary emotions; and Structural Deficit to all primary emotions (Figure 1). The model was controlled for age and sex. Furthermore, correlations between the disturbance terms of Personality Organization and attachment scales; between Depend, Anxiety, and Close; and between individual primary emotions were assigned.

After the initial model was fitted, a pruning strategy was applied in which nonsignificant paths were removed. First, nonsignificant correlations between the error terms of the individual variables were removed. Second, nonsignificant paths from Childhood Trauma to primary emotions were removed. Third, nonsignificant paths from Structural Deficit and the attachment scales to primary emotions were removed. Goodness-of-fit was assessed with a maximum likelihood estimation in AMOS. To test for mediation and indirect effects, a bootstrap was performed with a bias-corrected confidence interval of $95 \%$ and 1,000 bootstrap samples (52).

In accordance with Kline (53), the following fit indices were considered as markers for an acceptable model fit: (a) The comparative fit index (CFI) $>0.90$; (b) Tucker-Lewis index (TLI) relative fit index $>0.90$; (c) the square root error of approximation (RMSEA) $<0.08$ and the upper bound of its $90 \%$ confidence interval $<1$. For the comparison of competing models, the Bayesian information criterion (BIC) was used, with the smaller value indicating better fit.

\section{RESULTS}

\section{Sample Characteristics and Descriptive Statistics}

The investigated sample consisted of 616 German-speaking adults (381 female, 61.9\%). The participants ranged in age from 18 to 
69 years $(M=30 ; S D=9.53)$. A total of $231(37.5 \%)$ participants declared a university degree as their highest educational level, $214(34.7 \%)$ a general qualification for university entrance, $46(7.4 \%)$ a high school degree, and 96 (15.5\%) participants stated a completed apprenticeship as their highest educational level. Twenty-nine (4.7\%) participants stated that they left school without graduation. Regarding the current occupation of participants, 222 (36\%) were in employment, $313(50.8 \%)$ in education, 57 (9.2\%) were unemployed, and 24 (3.8\%) were on pension. Concerning the current relationship status, 59 (9.6\%) were married, 259 (42.0\%) in a relationship, and 298 (48.4\%) were single. The nationality of most participants was either German (n $=334 ; 54.5 \%)$, Austrian $(\mathrm{n}=218 ; 35.5 \%)$, or Swiss $(\mathrm{n}=30 ; 4.8 \%)$, whereas 34 (5.5\%) had other nationalities. Finally, 243 (39.4\%) participants declared that they had been diagnosed with a (lifetime) psychiatric disorder. The majority of these participants were diagnosed with depression $(\mathrm{n}=147 ; 60 \%), 50(21 \%)$ with other affective disorders, and 46 (19\%) participants were diagnosed with other psychiatric disorders. As shown in Table 1, participants with and without a psychiatric diagnosis differed $\left(p<0.001 ; \eta^{2}=0.03-0.15\right)$ in every examined variable, with the exception of CARE ( $p=$ n.s.). This included higher attachment security, less structural deficit, and less experienced childhood maltreatment in participants without psychiatric diagnosis.

As shown in Table 2, descriptive results suggested that the sample reported overall moderate exposure to childhood maltreatment $(M=36.50 ; S D=15.22)$ (46). Furthermore, bivariate correlations between the examined variables suggested that the Childhood Trauma total score was significantly positively related to Structural Deficit, Anxiety, ANGER, FEAR, and SADNESS (all $p<0.001$ ). Moreover, Childhood Trauma was negatively correlated with Depend, Close, SEEK, CARE, and PLAY (all $p<0.001$ ) but not to sex ( $p=$ n.s.) (see Table 2). In addition, Structural Deficit was associated with every attachment

TABLE 1 | Descriptive statistics and differences between participants with psychiatric diagnosis $(N=243)$ and without $(N=373)$.

\begin{tabular}{|c|c|c|c|c|c|c|c|c|}
\hline \multirow[t]{2}{*}{ Measure } & \multirow[t]{2}{*}{$\alpha$} & \multicolumn{2}{|c|}{ Healthy } & \multicolumn{2}{|c|}{ Diagnosis } & \multirow[t]{2}{*}{$F_{(1,614)}$} & \multirow[t]{2}{*}{$\mathbf{p}$} & \multirow[t]{2}{*}{$\eta^{2}$} \\
\hline & & $\mathbf{M}$ & SD & $\mathbf{M}$ & SD & & & \\
\hline \multicolumn{9}{|l|}{ AAS } \\
\hline Depend & 0.85 & 15.87 & 4.57 & 11.90 & 4.95 & 103.89 & 0.000 & 0.15 \\
\hline Close & 0.87 & 13.18 & 4.82 & 10.30 & 5.17 & 49.83 & 0.000 & 0.08 \\
\hline Anxiety & 0.81 & 11.07 & 4.52 & 13.68 & 5.12 & 44.38 & 0.000 & 0.07 \\
\hline \multicolumn{9}{|l|}{ IPO } \\
\hline Structural Deficit & 0.88 & 33.25 & 10.72 & 39.68 & 11.49 & 49.91 & 0.000 & 0.08 \\
\hline \multicolumn{9}{|l|}{ CTQ } \\
\hline Childhood Trauma & 0.93 & 32.64 & 12.84 & 42.44 & 16.65 & 67.52 & 0.000 & 0.10 \\
\hline \multicolumn{9}{|l|}{ ANPS } \\
\hline SEEK & 0.75 & 2.89 & 0.38 & 2.70 & 0.42 & 33.62 & 0.000 & 0.05 \\
\hline FEAR & 0.89 & 2.64 & 0.52 & 3.06 & 0.51 & 96.66 & 0.000 & 0.14 \\
\hline ANGER & 0.85 & 2.53 & 0.48 & 2.71 & 0.53 & 17.89 & 0.000 & 0.03 \\
\hline SADNESS & 0.78 & 2.52 & 0.48 & 2.87 & 0.43 & 99.73 & 0.000 & 0.14 \\
\hline CARE & 0.76 & 2.90 & 0.45 & 2.85 & 0.47 & 1.53 & 0.216 & 0.00 \\
\hline PLAY & 0.83 & 2.89 & 0.45 & 2.60 & 0.48 & 57.70 & 0.000 & 0.09 \\
\hline
\end{tabular}

AAS, Adult Attachment Scales; IPO, Inventory of Personality Organization; CTQ, Childhood Trauma Questionnaire; ANPS, Affective Neuroscience Personality Scales.

TABLE 2 | Descriptive statistics, sex differences, and correlations among examined variables.

\begin{tabular}{|c|c|c|c|c|c|c|c|c|c|c|c|c|}
\hline Variable & 1 & 2 & 3 & 4 & 5 & 6 & 7 & 8 & 9 & 10 & 11 & 12 \\
\hline 1. Childhood & - & & & & & & & & & & & \\
\hline \multicolumn{13}{|l|}{ Trauma } \\
\hline 2. Structural Deficit & $0.37^{*}$ & - & & & & & & & & & & \\
\hline 3. Close & $-0.44^{\star}$ & $-0.48^{*}$ & - & & & & & & & & & \\
\hline 4. Depend & $-0.55^{\star}$ & $-0.50^{\star}$ & $0.60^{\star}$ & - & & & & & & & & \\
\hline 5. Anxiety & $0.35^{\star}$ & $0.67^{\star}$ & $-0.37^{\star}$ & $-0.53^{\star}$ & - & & & & & & & \\
\hline 6. SEEK & $-0.24^{\star}$ & $-0.17^{\star}$ & $0.28^{*}$ & $0.34^{*}$ & $-0.20^{\star}$ & - & & & & & & \\
\hline 7. FEAR & $0.25^{\star}$ & $0.46^{*}$ & $-0.32^{*}$ & $-0.44^{*}$ & $0.55^{\star}$ & $-0.33^{\star}$ & - & & & & & \\
\hline 8. ANGER & $0.20^{*}$ & $0.34^{*}$ & $-0.20^{*}$ & $-0.32^{*}$ & $0.28^{\star}$ & -0.09 & $0.34^{\star}$ & - & & & & \\
\hline 9. SADNESS & $0.36^{*}$ & $0.51^{*}$ & $-0.36^{\star}$ & $-0.54^{*}$ & $0.65^{\star}$ & $-0.32^{\star}$ & $0.73^{*}$ & 0.37 & - & & & \\
\hline 10. CARE & $-0.14^{\star}$ & 0.08 & $0.28^{*}$ & $0.25^{\star}$ & 0.07 & $0.28^{*}$ & 0.09 & -0.06 & 0.06 & - & & \\
\hline 11. PLAY & $-0.34^{\star}$ & $-0.23^{*}$ & $0.53^{\star}$ & $0.53^{\star}$ & $-0.25^{\star}$ & $0.56^{\star}$ & $-0.39^{*}$ & -0.11 & $-0.41^{*}$ & $0.41^{*}$ & - & \\
\hline 12. Sex & 0.09 & -0.01 & 0.04 & 0.00 & 0.06 & 0.03 & $0.14^{\star}$ & 0.06 & $0.15^{\star}$ & $0.34^{*}$ & 0.03 & - \\
\hline$M$ or $n$ & 36.50 & 35.79 & 12.04 & 14.30 & 12.10 & 2.81 & 2.81 & 2.60 & 2.66 & 2.88 & 2.78 & 381 \\
\hline$S D$ or $\%$ & 15.22 & 11.47 & 5.15 & 5.10 & 4.93 & 0.40 & 0.55 & 0.51 & 0.45 & 0.43 & 0.48 & 61.9 \\
\hline
\end{tabular}

$n=616 ;{ }^{*} p<0.001 ;$ Sex was coded as $0=$ male; 1 = female. 
scale $(p<0.001)$ and every primary emotion $(p<0.001)$ with the exception of CARE ( $p=$ n.s.). Finally, all attachment scales were significantly related to every primary emotion scale $(p<0.001)$.

\section{Path Analysis Regarding the Relationship Between Childhood Trauma, Structural Deficit, Adult Attachment, and Primary Emotions}

An initial model proposed direct effects from Childhood Trauma to Structural Deficit, attachment dimensions, and the individual primary emotions, as well as direct effects from Structural Deficit and attachment scales to primary emotions (Figure 1). The model, which was corrected for age and sex, was saturated; hence, it was not possible to compute the probability level. The model was then pruned by deleting nonsignificant correlations between disturbance terms of the individual primary emotions. This included correlations between ANGER and SEEK, ANGER and CARE, and ANGER and PLAY.

This procedure yielded a model that fit the data well: RMSEA $=0.00$ (90\% CI: 0.00, 0.05); TLI = 1.00; CFI = 1.00; $\mathrm{BIC}=535.63$. In a further step, the model was pruned by removing nonsignificant paths. First, nonsignificant paths from Childhood Trauma to primary emotions were deleted. This included every association between Childhood Trauma and primary emotions. Second, nonsignificant paths from Structural Deficit and attachment dimensions to primary emotions were removed. This included (1) paths from Structural Deficit to SADNESS, FEAR, CARE, and SEEK; (2) paths from Close to FEAR, SADNESS, and ANGER; and (3) paths from Anxiety to ANGER, SEEK, and PLAY.

The trimmed model is presented in Figure 2. This model showed good fit: RMSEA $=0.03$ (90\% CI: 0.01, 0.05); TLI = 0.99; $\mathrm{CFI}=1.00 ; \mathrm{BIC}=490.35$. The reduction in $\mathrm{BIC}$ score was
$\Delta 45$, which indicated that this model was significantly more parsimonious than the initial model and therefore a better fit for the data.

\section{Direct Effects}

As shown in Figure 2, this model suggested that Childhood Trauma is significantly related to Structural Deficit $(\beta=0.39$; $p<0.001)$, Depend $(\beta=-0.56 ; p<0.001)$, Close $(\beta=-0.44 ; p<$ $0.001)$, and Anxiety $(\beta=0.36 ; p<0.001)$. Moreover, Structural Deficit showed a significant positive correlation with Anxiety $(r=0.60)$ and significant negative correlations with Depend $(r=-0.38)$ and Close $(r=-0.39$; all $p<0.001)$. Moreover, every attachment scale was correlated with each other $(p<0.001)$. In detail, Anxiety was negatively linked to Depend $(r=-0.43)$ and Close $(r=-0.26)$, whereas Depend was positively linked to Close $(r=0.47)$. Furthermore, Structural Deficit was associated with $\operatorname{ANGER}(\beta=0.21 ; p<0.001)$ and PLAY $(\beta=0.12 ; p<0.001)$. Meanwhile, Depend was associated with ANGER $(\beta=-0.21$; $p<0.001)$, SADNESS $(\beta=-0.29 ; p<0.001)$, SEEK $(\beta=0.29 ; p<$ $0.001), \operatorname{FEAR}(\beta=-0.25 ; p<0.001), \operatorname{PLAY}(\beta=0.41 ; p<0.001)$, and CARE $(\beta=0.24 ; p<0.001)$. In addition, Close was associated with PLAY $(\beta=0.33 ; p<0.001)$, SEEK $(\beta=0.10 ; p<0.02)$, and CARE $(\beta=0.25 ; p<0.001)$. Finally, Anxiety was associated with FEAR $(\beta=0.37 ; p<0.001)$, SADNESS $(\beta=0.47 ; p<0.001)$ and CARE $(\beta=0.27 ; p<0.001)$.

With regard to the control variables, female sex was positively associated with FEAR $(\beta=0.12 ; p<0.001)$ and CARE $(\beta=0.33$; $p<0.001)$, whereas age was negatively associated with Structural Deficit $(\beta=-0.25 ; p<0.001)$, Anxiety $(\beta=-0.24 ; p<0.001)$, FEAR $(\beta=-0.13 ; p<0.001)$, and PLAY $(\beta=-0.13 ; p<0.001)$.

In summary, this model was able to explain $14 \%$ of the variance of ANGER, $48 \%$ of SADNESS, $13 \%$ of SEEK, $35 \%$ of FEAR, $38 \%$ of PLAY, and $28 \%$ of CARE.

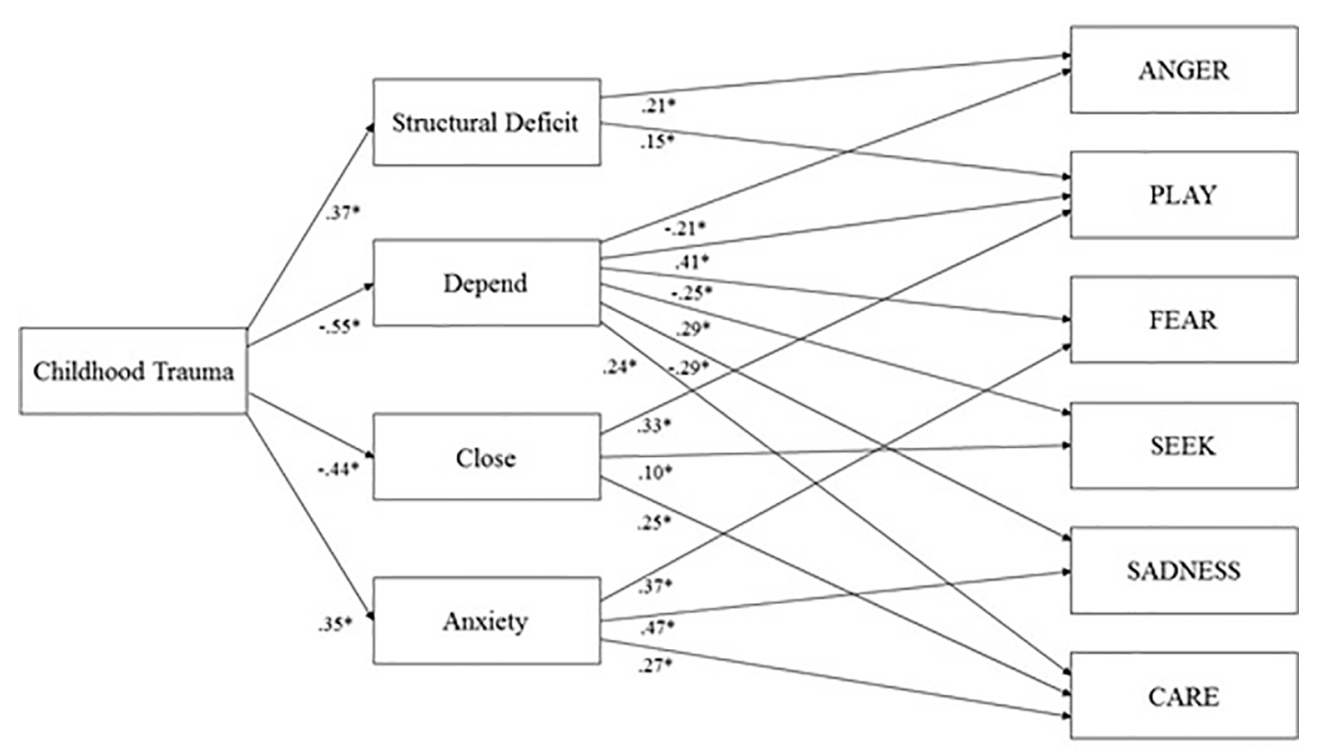

FIGURE 2 | Final model of Childhood Trauma, Structural Deficit, Adult attachment, and Primary Emotions controlled for Age and Sex; ${ }^{*} p<0.001$. 


\section{Indirect Effects}

Furthermore, bootstrap analysis revealed significant indirect effects of childhood trauma on primary emotions, mediated through its association with Structural Deficit and adult attachment. Significant indirect effects of Childhood Trauma include associations with CARE $(\beta=-0.15 ; p<0.01)$, mediated via Anxiety, Depend, and Close; SEEK $(\beta=-0.18 ; p<0.01)$, mediated by Close and Depend; ANGER $(\beta=0.20 ; p<0.01)$, mediated by Structural Deficit and Depend; PLAY $(\beta=-0.31 ; p<0.01)$, mediated by Structural Deficit, Depend, and Close; FEAR $(\beta=0.29 ; p<0.01)$, mediated by Structural Deficit, Depend, and Anxiety; and SADNESS $(\beta=0.31 ; p<0.01)$, mediated by Depend and Anxiety.

\section{Multigroup Path Analysis}

We further tested if healthy participants differed from participants with a psychiatric diagnosis regarding the relationships in the path model. The results revealed that both groups showed no significant differences in their path associations regarding the global model $\left(\chi_{(19)}^{2}=23.66 ; p=\right.$ n.s. $)$.

\section{DISCUSSION}

This study investigated the role of adult attachment and personality organization regarding the relationship between childhood trauma and adult life primary emotion functioning. Path analytic estimations concerning the indirect relationship between childhood trauma and primary emotions support the assumption that the influence of childhood trauma on primary emotion dispositions in adults is mediated by deficits in personality organization and insecure attachment. These results are largely in accordance with a growing field of research studies linking childhood trauma to emotion dysregulation and emotional dysfunctioning (3-5). Moreover, the results of the estimated direct effects suggest that the relationship between emotional dysfunctioning and childhood trauma might be the result of dysfunctional internalization processes related to traumatic early object relations, which lead to deficits in personality organization and insecure attachment patterns in the adult mental apparatus $(9,24)$. Furthermore, this study was able to gather evidence for the clinical significance of the AN-framework. In accordance with this, participants diagnosed with a psychiatric disorder not only exhibited more childhood trauma but also showed more deficits, in comparison to healthy participants, in all secondary order concepts as well as increased negative primary emotion dispositions and decreased dispositions in almost all positive primary emotions.

Our results underline the assumed importance of personality organization and adult attachment in emotional functioning proposed in psychodynamic literature $(9,20,23$, 54) and deepen the understanding of this connection. When computed within a single model, we find that structural deficit is significantly associated with increased PLAY and ANGER, whereas attachment dimensions are related to the measured primary emotion dispositions in general. More specifically, comfort with dependence on others shows several associations to decreased ANGER, FEAR, and SADNESS and increased PLAY, SEEK, and CARE. Comfort with closeness is linked with increased PLAY, SEEK, and CARE, and anxiety about being rejected or unloved predicts increased FEAR, SADNESS, and CARE. These results suggest that deficits in personality organization and insecure attachment mainly foster primary emotional traits, which are experienced as unpleasant (ANGER, FEAR, and SADNESS), whereas secure attachment predominately fosters pleasant primary emotion dispositions (SEEK, PLAY, and CARE). This is with the exception of "anxiety of being rejected," which is linked to increased CARE, reflecting the relationship of this concept with the insecure ambivalent or preoccupied attachment style, which is characterized by excessive clinging to attachment figures $(55,56)$. Furthermore, the rather small relationship between deficits in personality organization and increased PLAY might be caused by a suppression effect in our path model, as correlation analysis suggested an inverse relationship between these two concepts. In summary, the relationship among attachment, personality organization, and emotional functioning might be explained, in accordance with basic assumptions of attachment and object relations theory, by the affect-integrating role of underlying internalized working models and object relations $(9,20,54,57)$.

Notably, deficits in personality organization are predominantly related to increased levels of ANGER compared to adult attachment. This result echoes Kernberg's (9, 32, 58) conceptualization of personality organization, which (in line with Kleinian object relation theory) (59) emphasizes its crucial role in the integration and neutralization of aggressive affects. In contrast, adult attachment demonstrated stronger relations with every other facet of primary emotion dispositions, highlighting the importance of secure attachment in affect regulation and emotional functioning $(20,60)$.

With regard to proposed neural correlates of affect regulation, linked to the prefrontal and anterior cingulate cortex $(61,62)$, future studies might further investigate the functional and structural relationship between these neocortical areas and childhood trauma, adult attachment patterns, as well as personality organization. Furthermore, with regard to ANGER, which according to Panksepp (63) is mediated largely by a complex neural network, including the medial amygdala, the bed nucleus of the stria terminalis, the medial and perifornical hypothalamus, and dorsolateral parts of the periaqueductal gray, it seems plausible that the individual's personality organization might also impact functional properties of these structures. Therefore, future studies might aim to examine the influence of therapeutic interventions directed at the improvement of personality organization based on their effect on these subcortical regions. Specifically, this might include research on neurofunctional effects of psychodynamic and attachment oriented intervention strategies like Mentalization Based Therapy (64) or Transference Focused Psychotherapy (65). Furthermore, 
another good example might be Mindfulness meditation techniques, which were observed to positively influence feelings of anger and anxiety in clinical patient groups (7, $66,67)$. Moreover, there is a plethora of pharmacological compounds that were found to be effective in anger treatment, including mood stabilizers, serotonergic medication, and antipsychotics (68). Therefore, future research might aim to investigate the differential psychodynamic effects of psychopharmacological medications.

The direct paths of the investigated model increased the understanding of the relationship between personality organization and adult attachment. In line with previous theoretical and empirical studies $(23,36,38,41,45)$ correlation analysis revealed substantial links between personality organization and adult attachment, which reflects conceptual similarities of both concepts. The strength of the relationships ranged from medium negative correlations with "comfort with dependence and closeness" to a large positive correlation with "anxiety of being rejected" (69). Moreover, correlation analysis revealed substantial links between emotional functioning and personality organization in addition to adult attachment. However, because of the substantial correlations between both personality organization and adult attachment, the influence of personality organization on primary emotions is diminished by adult attachment, if both concepts are considered within a single model.

The results of the multigroup analysis indicated no significant difference between healthy and diagnosed participants regarding the strength and direction of the relationship between childhood trauma, adult attachment, structural deficit, and primary emotion functioning. Therefore, this finding suggested a continuum model regarding the relationship between childhood trauma and adult personality and psychopathology.

Some limitations of this study should be noted. Despite applying path analysis, the design of this study was crosssectional. Therefore, the investigated pathways among adult attachment, personality organization, and primary emotions cannot be seen as strictly causal. Future research might therefore conduct longitudinal studies to explore the predictive links between these concepts. Furthermore, our sample contained a rather large proportion of participants with a wide range of psychiatric disorders. This might have led to confounding effects within our model. Although multigroup analysis regarding differences between participants with and without psychiatric disorders revealed no significant difference between these groups, future work should focus on differences within the relationships between these concepts in relation to groups differing in psychopathology. Therefore, psychiatric disorders should be assessed more thoroughly by means of standardized clinical interviews. Nevertheless, it seemed reasonable for this explorative study to investigate a continuum between health and pathology. Furthermore, the attrition rate within our sample was relatively high (58\%), which might suggest a certain amount of reactivity to the questions and could a have had an impact on the representativeness of the data. Moreover, the use of self-rating measures in regard to concepts, which are at least partly regarded as unconscious (61), might be seen as insufficient because they only map the conscious surface structures of these concepts. Therefore, future studies applying structured interviews should be conducted to strengthen the validity of our results. Lastly, this study did not apply measurements to assess possible self-presentation bias, hence, we cannot rule out that diminished abilities of self-reflection or tendencies toward distorted self-presentation might have influenced our results.

\section{CONCLUSION}

The current study contributes to the knowledge of how childhood trauma, attachment insecurity, and deficits in personality organization influence emotional functioning. Our results suggest that both attachment and personality organization explain the association between abuse experienced in childhood and primary emotion functioning in adult life. These findings indicate that the AN-framework, assuming linked primary and higher order processes (7), might be valuable avenues to understand the pathogenic effects of childhood trauma. Therefore, this work underlines the importance of attachment and personality organization for the treatment of psychiatric disorders associated with emotional dysfunctioning $(57,70)$. In accordance with this, psychotherapeutic interventions might focus on traumatically damaged object relations and the restructuring of dysfunctional personality organization and attachment patterns to foster increased self-regulation and emotional functioning in patients.

\section{ETHICS STATEMENT}

This study was carried out in accordance with the recommendations of the ethics guidelines of the Medical University of Graz. The protocol was approved by the ethics committee of the Medical University of Graz. All subjects gave written informed consent in accordance with the Declaration of Helsinki.

\section{AUTHOR CONTRIBUTIONS}

JF and HU conceptualized the study. JF collected, analyzed and interpreted the data. JF, HU, and MH-R drafted the manuscript. $\mathrm{AK}$ and H-PK critically reviewed the manuscript. All authors gave their final approval of the manuscript.

\section{ACKNOWLEDGMENTS}

We would like to acknowledge the work of Nikolas Bonatos for making helpful and invaluable critical comments about the manuscript. 


\section{REFERENCES}

1. van Nierop M, Viechtbauer W, Gunther N, van Zelst C, de Graaf R, ten Have $\mathrm{M}$, et al. Childhood trauma is associated with a specific admixture of affective, anxiety, and psychosis symptoms cutting across traditional diagnostic boundaries. Psychol Med (2015) 45:1277-88. doi: 10.1017/ S0033291714002372

2. Teicher MH, Samson JA. Annual research review: enduring neurobiological effects of childhood abuse and neglect. J Child Psychol Psychiatry (2016) 57:241-66. doi: 10.1111/jcpp. 12507

3. Heim C, Nemeroff CB. The role of childhood trauma in the neurobiology of mood and anxiety disorders. preclinical and clinical studies. Biol Psychiatry (2001) 49:1023-39. doi: 10.1016/S0006-3223(01)01157-X

4. Pechtel P, Pizzagalli DA. Effects of early life stress on cognitive and affective function: an integrated review of human literature. Psychopharmacology (2011) 214:55-70. doi: 10.1007/s00213-010-2009-2

5. Tottenham N, Hare TA, Quinn BT, McCarry TW, Nurse M, Gilhooly T, et al. Prolonged institutional rearing is associated with atypically large amygdala volume and difficulties in emotion regulation. Dev Sci (2010) 13:46-61. doi: 10.1111/j.1467-7687.2009.00852.x

6. Bernstein DP, Ahluvalia T, Pogge D, Handelsman L. Validity of the childhood trauma questionnaire in an adolescent psychiatric population. J Am Acad Child Adolesc Psychiatry (1997) 36:340-8. doi: 10.1097/ 00004583-199703000-00012

7. Panksepp J, Biven L. The archaeology of mind: Neuroevolutionary origins of human emotions. New York: WW Norton \& Company (2012).

8. Panksepp J, Solms M. What is neuropsychoanalysis? clinically relevant studies of the minded brain. Trends Cogn Sci (2012) 16:6-8. doi: 10.1016/j. tics.2011.11.005

9. Kernberg OF. Neurobiological correlates of object relations theory. the relationship between neurobiological and psychodynamic development. Int Forum Psychoanal (2015) 24(1):38-46. doi: 10.1080/0803706X.2014.912352

10. Davis KL, Panksepp J, Normansell L. The affective neuroscience personality scales. Normative dataandimplications. Neuropsychoanalysis (2003) 5:57-69. doi: 10.1080/15294145.2003.10773410

11. Montag C, Widenhorn-Müller K, Panksepp J, Kiefer M. Individual differences in Affective Neuroscience Personality Scale (ANPS) primary emotional traits and depressive tendencies. Compr Psychiatry (2017) 73:13642. doi: 10.1016/j.comppsych.2016.11.007

12. Fuchshuber J, Hiebler-Ragger M, Kresse A, Kapfhammer H-P, Unterrainer HF. Depressive symptoms and addictive behaviors in young adults after childhood trauma: the mediating role of personality organization and despair. Front Psychiatry (2018) 9:318. doi: 10.3389/fpsyt.2018.00318

13. Orri M, Pingault J-B, Rouquette A, Lalanne C, Falissard B, Herba C, et al. Identifying affective personality profiles: a latent profile analysis of the affective neuroscience personality scales. Sci Rep (2017) 7:4548. doi: 10.1038/ s41598-017-04738-x

14. Unterrainer HF, Hiebler-Ragger M, Koschutnig K, Fuchshuber J, Tscheschner S, Url M, et al. Addiction as an attachment disorder: white matter impairment is linked to increased negative affective states in polydrug use. Front Neurosci (2017) 11:208. doi: 10.3389/fnhum.2017.00208

15. Montag C, Sindermann C, Becker B, Panksepp J. An affective neuroscience framework for the molecular study of internet addiction. Front Psychol (2016) 7. doi: 10.3389/fpsyg.2016.01906

16. Carré A, Chevallier C, Robel L, Barry C, Maria A-S, Pouga L, et al. Tracking social motivation systems deficits: the affective neuroscience view of autism. J Autism Dev Disord (2015) 45:3351-63. doi: 10.1007/s10803-015-2498-2

17. Melchers M, Plieger T, Montag C, Reuter M, Spinath FM, Hahn E. The heritability of response styles and its impact on heritability estimates of personality: a twin study. Personal Individ Differ (2018) 134:16-24. doi: $10.1016 /$ j.paid.2018.05.023

18. Watt DF, Panksepp J. Depression. An evolutionarily conserved mechanism to terminate separation distress? A review of aminergic, peptidergic, and neural network perspectives. Neuropsychoanalysis (2009) 11:7-51. doi: 10.1080/15294145.2009.10773593

19. Zellner MR, Watt DF, Solms M, Panksepp J. Affective neuroscientific and neuropsychoanalytic approaches to two intractable psychiatric problems.
Why depression feels so bad and what addicts really want. Neurosci Biobehav $\operatorname{Rev}(2011)$ 35:2000-8. doi: 10.1016/j.neubiorev.2011.01.003

20. Schore JR, Schore AN. Modern attachment theory. The central role of affect regulation in development and treatment. Clin Soc Work J (2008) 36:9-20. doi: 10.1007/s10615-007-0111-7

21. Bowlby J. Attachment and Loss: Attachment. New York: Basic Books (1969).

22. Schore AN. Dysregulation of the right brain. A fundamental mechanism of traumatic attachment and the psychopathogenesis of posttraumatic stress disorder. Aust N Z J Psychiatry (2002) 36:9-30. doi: 10.1046/j.1440-1614.2002.00996.x

23. Fonagy P. Attachment, trauma, and psychoanalysis: Where psychoanalysis meets neuroscience. In: Canestri J, Leuzinger-Bohleber M, Target M, editors. Early development and its disturbances: Clinical, conceptual and empirical research on $A D H D$ and other psychopathologies and its epistemological reflections. Karnac Books (2010). p. 53-75. doi: 10.4324/9780429474057-2

24. Fonagy P. Bindungstheorie und Psychoanalyse. Stuttgart: Klett-Cotta (2003).

25. Flores PJ. Addiction as an attachment disorder. Lanham: Jason Aronson (2004).

26. Schmidt S, Strauss B, Höger D, Brähler E. The Adult Attachment Scale (AAS)psychometric evaluation and normation of the German version. Psychother Psychosom Med Psychol (2004) 54:375-82. doi: 10.1055/s-2003-815000

27. Belsky J. Interactional and contextual determinants of attachment security. In: Cassidy J, Shaver PR, editors. Handbook of attachment: Theory, research, and clinical applications. Rough Guides (2002). p. 249-64.

28. Fonagy P, Luyten P, Strathearn L. Borderline personality disorder, mentalization, and the neurobiology of attachment. Infant Ment Health J (2011) 32:47-69. doi: 10.1002/imhj.20283

29. Schore AN. The effects of early relational trauma on right brain development, affect regulation, and infant mental health. Infant Ment HealthJ(2001) 22:20169. doi: 10.1002/1097-0355(200101/04)22:1<201::AID-IMHJ8>3.0.CO;2-9

30. Kernberg OF. Objektbeziehungen und Praxis der Psychoanalyse. Stuttgart: Klett-Cotta (1988).

31. Greenberg J. Object relations in psychoanalytic theory. Harvard: Harvard University Press (1983). doi: 10.2307/j.ctvjk2xv6

32. Kernberg OF. Severepersonalitydisorders: Psychotherapeuticstrategies. Yale: Yale University Press (1993).

33. Kernberg OF, Caligor E. A Psychoanalytic Theory of Personality Disorders. In: Lenzenweger MF, Clarkin JF, editors. Major theories of personality disorder. Guilford Press (2005). p. 106-40.

34. Zimmermann J, Benecke C, Hörz S, Rentrop M, Peham D, Bock A, et al. Validierung einer deutschsprachigen 16-item-Version des Inventars der Persönlichkeitsorganisation (IPO-16). Diagnostica (2013) 59:3-16. doi: 10.1026/ 0012-1924/a000076

35. Lenzenweger MF, Clarkin JF, Kernberg OF, Foelsch PA. The inventory of personality organization. psychometric properties, factorial composition, and criterion relations with affect, aggressive dyscontrol, psychosis proneness, and self-domains in a nonclinical sample. Psychol Assess (2001) 13:577-91. doi: 10.1037/1040-3590.13.4.577

36. Ainsworth MDS. Object relations, dependency, and attachment: A theoretical review of the infant-mother relationship. Child Dev (1969) 40:969-1025. doi: 10.1111/j.1467-8624.1969.tb04561.x

37. Clarkin JF, Lenzenweger MF, Yeomans F, Levy KN, Kernberg OF. An object relations model of borderline pathology. J Pers Disord (2007) 21:474-99. doi: 10.1521/pedi.2007.21.5.474

38. Fonagy P. Psychoanalytic theory from the viewpoint of attachment theory and research. In: Cassidy J, Shaver PR, editors. Handbook of attachment: Theory, research, and clinical applications. Rough Guides (2002). p. 595-624.

39. Agrawal HR, Gunderson J, Holmes BM, Lyons-Ruth K. Attachment studies with borderline patients: A review. Harv Rev Psychiatry (2004) 12:94-104. doi: 10.1080/10673220490447218

40. Levy KN. The implications of attachment theory and research for understanding borderline personality disorder. Dev Psychopathol (2005) 17:959-86. doi: 10.1017/S0954579405050455

41. Fischer-Kern M, Buchheim A, Hörz S, Schuster P, Doering S, Kapusta ND, et al. The relationship between personality organization, reflective functioning, and psychiatric classification in borderline personality disorder. Psychoanal Psychol (2010) 27:395-409. doi: 10.1037/a0022611 
42. Fonagy P, Target M, Steele H, Steele M. Reflective-functioning manual, version 5.0, for application to adult attachment interviews. London: Univ Coll London (1998) 161-2. doi: 10.1037/t03490-000

43. George C, Kaplan N, Main M. Adult attachment interview. Berkeley: University of California (1996). Unpublished manuscript.

44. Clarkin JF, Caligor E, Stern B, Kernberg OF. Structured interview of personality organization (STIPO). Weill Med Coll Cornell Univ (2004).

45. Hiebler-Ragger M, Unterrainer H-F, Rinner A, Kapfhammer H-P. Insecure attachment styles and increased borderline personality organization in substance use disorders. Psychopathology (2016) 49:341-4. doi: 10.1159/ 000448177

46. Wingenfeld K, Spitzer C, Mensebach C, Grabe HJ, Hill A, Gast U, et al. The German version of the Childhood Trauma Questionnaire (CTQ). Preliminary psychometric properties. Psychother Psychosom Med Psychol (2010) 60:442-50. doi: 10.1055/s-0030-1247564

47. Kilpatrick DG, Acierno R, Saunders B, Resnick HS, Best CL, \& Schnurr PP. Risk factors for adolescent substance abuse and dependence: data from a national sample. J Consul Clin Psychol (2000) 68(1):19-30.

48. Reuter M, Henning J. Affective Neuroscience Personality Scales (ANPS). German Version. University of Giessen (2014). Unpublished manuscript.

49. Reuter M, Panksepp J, Davis K, Montag C. Affective Neuroscience Personality Scales (ANPS)-Deutsche Version. Hogrefe-Verlag (2017).

50. Panksepp J. Affective neuroscience: The foundations of human and animal emotions. Oxford: Oxford university press (1998).

51. Collins NL, Read SJ. Adult attachment, working models, and relationship quality in dating couples. J Pers Soc Psychol (1990) 58:644-63. doi: 10.1037// 0022-3514.58.4.644

52. Cheung GW, Lau RS. Testing mediation and suppression effects of latent variables. Bootstrapping with structural equation models. Organ Res Meth (2008) 11:296-325. doi: 10.1177/1094428107300343

53. Kline RB. Principles and practice of structural equation modeling. New York: Guilford publications (2015).

54. Kernberg OF. Psychoanalytic affect theory in the light of contemporary neurobiological findings. Int Congr Ser (2006) 2006:106-17. doi: 10.1016/j. ics.2005.10.011

55. Ainsworth MDS, Bell SM. Attachment, exploration, and separation. Illustrated by the behavior of one-year-olds in a strange situation. Child Dev (1970) 41:49-67. doi: 10.1111/j.1467-8624.1970.tb00975.x

56. Bartholomew K, Horowitz LM. Attachment styles among young adults. A test of a four-category model. J Pers Soc Psychol (1991) 61:226-44. doi: 10.1037//0022-3514.61.2.226

57. Schore AN. Affect regulation and the origin of the self: The neurobiology of emotional development. Abingdon: Routledge (2015). doi: 10.4324/9781315680019

58. Kernberg OF. Borderline conditions and pathological narcissism. Lanham: Rowman\&Littlefield (1985).

59. Klein M. Notes on some schizoid mechanisms. Int J Psychoanal (1946) 27:99-110.
60. Mikulincer M, Shaver PR, Pereg D. Attachment theory and affect regulation: the dynamics, development, and cognitive consequences of attachment-related strategies. Motiv Emot (2003) 27:77-102. doi: 10.1023/ A: 1024515519160

61. Solms M, Panksepp J. The "Id" knows more than the "Ego" admits. Neuropsychoanalytic and primal consciousness perspectives on the interface between affective and cognitive neuroscience. Brain Sci (2012) 2:147-75. doi: 10.3390/brainsci2020147

62. Roth G, Dicke U. Funktionelle neuroanatomie des limbischen systems. In: Förstl H, Hautzinger M, Roth G, editors. Neurobiologie psychischer störungen. Springer (2006). p. 1-74. doi: 10.1007/3-540-30887-3_1

63. Panksepp J. The basic emotional circuits of mammalian brains: do animals have affective lives? Neurosci Biobehav Rev (2011) 35:1791-804. doi: 10.1016/ j.neubiorev.2011.08.003

64. Fonagy P, Bateman AW. Mechanisms of change in mentalization-based treatment of BPD. J Clin Psychol (2006) 62:411-30. doi: 10.1002/ jclp. 20241

65. Kernberg OF, Yeomans FE, Clarkin JF, Levy KN. Transference focused psychotherapy: overview and update. Int J Psychoanal (2008) 89:601-20. doi: 10.1111/j.1745-8315.2008.00046.x

66. Gaiswinkler L, Kaufmann P, Pollheimer E, Ackermann A, Holasek S, Kapfhammer H-P, et al. Mindfulness and Self-Compassion in Clinical Psychiatric Rehabilitation: a Clinical Trial. Mindfulness (2019) 1-10. doi: 10.1007/s12671-019-01171-1

67. Wright S, Day A, Howells K. Mindfulness and the treatment of anger problems. Aggression Violent Behav (2009) 14:396-401. doi: 10.1016/j.avb. 2009.06.008

68. Mercer D, Douglass AB, Links PS. Meta-analyses of mood stabilizers, antidepressants and antipsychotics in the treatment of borderline personality disorder: effectiveness for depression and anger symptoms. J Pers Disord (2009) 23:156-74. doi: 10.1521/pedi.2009.23.2.156

69. Cohen J. A power primer. Psychol Bull (1992) 112:155-9. doi: 10.1037//0033-2909.112.1.155

70. Panksepp J. Textbook of biological psychiatry. Hoboken: John Wiley \& Sons (2004). doi: 10.1002/0471468975

Conflict of Interest Statement: The authors declare that the research was conducted in the absence of any commercial or financial relationships that could be construed as a potential conflict of interest.

Copyright (C) 2019 Fuchshuber, Hiebler-Ragger, Kresse, Kapfhammer and Unterrainer. This is an open-access article distributed under the terms of the Creative Commons Attribution License (CC BY). The use, distribution or reproduction in other forums is permitted, provided the original author(s) and the copyright owner(s) are credited and that the original publication in this journal is cited, in accordance with accepted academic practice. No use, distribution or reproduction is permitted which does not comply with these terms. 